\title{
Employment Prospects of Young Adults With Mental Disorders
}

\author{
Isabel Baumann*, Szilvia Altwicker-Hámori** , Sibylle Juvalta**, \\ Niklas Baer***, Ulrich Frick****, and Peter Rüesch**
}

Abstract: We examine how type of diagnosis, educational trajectories and educational qualifications affect the employment prospects of young adults with mental disorders. We draw on a novel dataset based on data from the Swiss Federal Social Insurance Office. Our analysis shows that individuals with mental disorders that typically have an onset in early childhood, those who experience educational trajectories including special needs education, and those attaining higher levels of qualification are more likely to be employed in early adulthood.

Keywords: mental disorders, young adults, vulnerability, education, employment

\section{Berufliche Perspektiven junger Erwachsener mit psychischen Störungen}

Zusammenfassung: Wir untersuchen, wie Diagnose, Bildungslaufbahn und Bildungsabschlüsse die berufliche Perspektive von jungen Erwachsenen mit psychischen Störungen beeinflussen. Wir verwenden einen neuen Datensatz, erstellt auf der Basis von Daten des Bundesamts für Sozialversicherungen. Unsere Analyse zeigt, dass Individuen mit früh einsetzenden psychischen Störungen, einer Bildungslaufbahn, die den Besuch einer Sonderschule beinhaltet und jene, die höhere Bildungsabschlüsse erreicht haben, eine höhere Chance haben, im frühen Erwachsenenalter erwerbstätig zu sein.

Schlüsselwörter: Psychische Störungen, junge Erwachsene, Vulnerabilität, Bildung, Beschäftigung

\section{Perspectives professionnelles de jeunes adultes présentant des troubles psychiques}

Résumé: Nous examinons comment le diagnostic, les trajectoires scolaires et les diplômes influencent les perspectives professionnelles de jeunes adultes présentant des troubles mentaux. Nous utilisons une base de données créée à partir de données de l'Office fédéral des assurances sociales. Notre analyse montre que les chances d'obtenir un emploi au début de l'âge adulte sont plus importantes pour les individus dont les troubles mentaux sont survenus dans l'enfance, dont la trajectoire inclut une formation spécialisée et dont les diplômes obtenus sont élevés.

Mots-clés: troubles mentaux, jeunes adultes, vulnérabilité, formation, emploi

\footnotetext{
* Swiss National Centre of Competence in Research "Overcoming Vulnerabilities: Life Course Perspectives" (NCCR LIVES) and Zurich University of Applied Sciences ZHAW, CH-8400 Winterthur, isabel.baumann@zhaw.ch.

** Zurich University of Applied Sciences ZHAW, CH-8400 Winterthur, szilvia.altwicker-hamori@zhaw.ch, sibylle.juvalta@zhaw.ch, peter.rueesch@zhaw.ch.

*** Office for Psychiatric Rehabilitation, Psychiatric Services Baselland, CH-4410 Liestal, niklas.baer@pbl.ch.

**** HSD University of Applied Sciences, D-50676 Cologne, u.frick@hs-doepfer.de.
} 


\section{Introduction ${ }^{1}$}

In recent decades, the incidence of mental disorders ${ }^{2}$ among adolescents and young adults has increased in most OECD countries (Richter and Berger 2013; OECD 2014), although the increase has been mainly attributed to changing perceptions and health competences with respect to mental illness at a societal level (Pescosolido et al. 2010; Reavley and Jorm 2012). The one year prevalence rate is high, with an average of 25\% in OECD countries and 17\% in Switzerland (OECD 2012; OECD 2014). These figures have to be seen in light of the lower prevalence of chronicity of mental disorders among youth in comparison with the average population (OECD 2012).

A vast body of literature indicates that mental health problems in early life stages translate into less favorable life outcomes (McLeod and Almazan 2003). For instance, it has been shown that externalizing and attention disorders at ages 3 and 5 have negative consequences for individuals' further cognitive development (Turney and McLanahan 2015). Another study including physical and mental health issues found a strong and persisting effect of poor health on reading and mathematical skills (Jackson 2015). A longitudinal study examining mental health trajectories during childhood found that permanently high levels of poor mental health were associated with being without basic education and out of education, employment or training at age 19 (Veldman et al. 2015). Other authors emphasize that individuals with severe mental disorders have wages about a third below median wages (Levinson et al. 2010).

These disadvantages may translate into further adverse outcomes. For instance, being excluded from the labor market may preclude individuals from important social contacts and participation in society (Jahoda 1981; Holzner et al. 1998; Gallie and Paugam 2002). Being without or in low-paid employment creates restrictions in spending and saving and impedes financial independence (Andersen 2002). Being in a precarious situation may chronically worsen individuals' well-being, which in turn exacerbates their mental illness (Cook and Razzano 2000; Rüesch et al. 2004).

Individuals with an early onset thus seem to be vulnerable to further negative outcomes. The concept of vulnerability refers to a lack of resources (Ranci 2010; Spini et al. 2013) implying that individuals with a lack of resources in the domains of health or education cannot realize their opportunities in the labor market (Spini et al. 2017). One approach to explain the pathway into vulnerability is the theory of cumulative advantages and disadvantages developed by Dannefer (2003). In this view, advantages/disadvantages in early life reinforce the chance/risk of experiencing

1 We are grateful to Benjamin Baviera, Derya Cetinkaya, Annette Krauss, Lucien Wampfler and Sandra Wettstein for their excellent research assistance. We would like to thank Ignacio Madero-Cabib, Gaëlle Aeby and three anonymous reviewers for their very valuable comments. We acknowledge that data access was provided by the Swiss Federal Social Insurance Office. 
new advantages/disadvantages in later life. In the context of mental disorders in the young, mental illness with onset in early childhood constitutes a disadvantage that may translate into the risk of not completing education - for instance by dropping out of school - which in turn would lead to additional disadvantages - such as not successfully managing the transition from education to employment.

Our study examines the employment prospects of young adults with mental disorders, comparing the effects of type of diagnosis, educational trajectory and educational qualifications. We draw on a novel dataset of about 500 young adults with mental disorders based on data from the Swiss Federal Social Insurance Office (FSIO). Data analysis was performed using descriptive, sequence, cluster and regression analyses.

\section{The determinants of employment prospects of individuals with mental disorders}

\subsection{The effect of diagnoses and timing of onset}

Individuals with and without mental disorders differ substantially in educational outcomes (Burchardt 2005). Based on longitudinal data from Australia and the United States, it has been shown that among adolescents with mental disorders about one quarter have left school without a diploma, a share that is significantly higher than among adolescents without mental disorders (OECD 2012). A Swiss study based on the FSIO's medical records of individuals receiving disability benefits due to psychogenic and milieu-reactive disorders, reveals that having no higher qualification than mandatory schooling is almost twice more frequent among the target population than among the average Swiss population (Baer et al. 2009). Moreover, it seems that a very early onset of mental disorders and particular illnesses make individuals especially vulnerable to dropping out of school. A study from the US finds an association between mental disorders with onset in early childhood and primary school termination rates (Breslau et al. 2008). High-school graduation rates are particularly low in pupils with conduct disorders and/or substance use disorder but less in pupils with mood and anxiety disorders.

The timing of onset of mental disorder is also relevant in the context of the stratification of the Swiss educational systems (as discussed later). The selection into the different tracks starts in many cantons at the beginning of secondary education and evidence indicates that there is little mobility between the tracks (Shavit and Müller 2000). As a consequence, individuals with an early onset of mental disorders may be disadvantaged in comparison to those with a later onset.

Like educational attainment, the labor-market integration of individuals with mental disorders is often strongly curtailed. Using an instrumental variable approach to address selection bias, Chatterji et al. (2011) show that individuals 
suffering from a psychiatric disorder are 9 to 19 percentage points less likely to be in employment during the subsequent year. From systematic reviews it is known that only $10 \%$ of former psychiatric patients who are capable and wish to work are successful in finding any employment (Harnois and Gabriel 2000). In addition, the type of diagnosis is associated with differences in types of employment. Rüesch et al. (2002) examined the occupational outcomes of individuals with schizophrenic or affective disorders and found that in-patients with schizophrenia are over-represented in sheltered employment, whereas a higher proportion of in-patients suffering from an affective disorder was found in unpaid employment-like activities such as education, child-care or housework.

\subsection{The Swiss school system with a focus on special needs education}

The school system in Switzerland is organized at the cantonal level. However, in all cantons it includes 11 years of compulsory school and most cantons have a system that is structured in two years of Kindergarten, six years of primary school and three years of lower-secondary education. Kindergarten usually starts at age four or five and most children finish their lower-secondary education at age 16 . Lower-secondary education is stratified in some cantons and children are selected into different tracks (SKBF 2014). The selection is based on requirements in terms of educational performance but, as in other countries, it is likely that parents' socio-economic background also affects these selection mechanisms, for instance by determining preference for more or less risky and costly educational trajectories (Shavit and Müller 2000; Boone and Van Houtte 2013).

Lower secondary education is most often followed by upper-secondary education which usually consists either in high-school or vocational education and training (VET). Switzerland's educational system has a strong vocational training component and about two thirds of adolescents finish compulsory school enrolling in VET (SBFI 2016). The Swiss educational system distinguishes between twoyear, three-year and four-year VET programs, where the latter represents the most comprehensive of these programs.

With respect to special needs education, the system distinguishes between special needs schools, i. e. schools exclusively for children with special needs, and special classes, i. e. classes for children with special needs within regular schools (BFS 2010). There was a slight increase in the number of children who attended special needs education between the early 1990s and 2008, whereas after 2008 the numbers have dropped sharply. These fluctuations are mainly due to changes in age-group sizes and policies such as integration of children with special needs into regular classes. In 2016, about 31000 children were taught in special schools (including language classes for children with foreign mother tongue) which represented about $3 \%$ of all children in mandatory schooling (BFS 2016). 
Whereas in some cantons children with special needs are sent to special needs education schools, in other cantons they are integrated within regular schools, receiving individual support lesson by lesson. Whether children attend special needs education and how much support they receive depends on the severity of their disorder (BFS 2016). However, since the passing of the United Nations Convention on the Rights of Persons with Disabilities in 2014, the cantons have to implement the policy of integrated schooling (United Nations 2008). Implementation nonetheless varies between cantons.

\subsection{The effect of special needs education}

In the international literature on the effects of special needs education there is a debate as to whether it improves or impairs individuals' educational outcomes. On the one hand, proponents of the impairment thesis claim that special needs education goes along with marginalization which decreases children's chances of gaining credentials (Alexander et al. 1997; Janosz et al. 2008). Studies from the United States unequivocally reveal an association of special school attendance and school dropout. For instance, in a longitudinal study on school dropout based on a sample of children from Baltimore, the authors find that those in special needs education have a higher risk of school dropout (Alexander et al. 1997). However, this result may be due to the fact that in the United States special needs education attendance is more frequent among members of low socio-economic classes, which is in turn associated with school dropout. This finding may due to selection effects, an assumption that is supported by earlier research showing that there is a social gradient of mental health (Patel et al. 2010).

On the other hand, proponents of the improvement thesis argue that special needs education provides individuals with the opportunity to attain a qualification (Humphrey et al. 2013; Kern et al. 2015). A quasi-experimental study in the UK examined the effect of a school-based intervention to provide children with special needs (not specifically with mental disorders) with support, for instance regarding behavior problems and bullying (Humphrey et al. 2013). The authors found that the intervention generally had a positive effect on children's behavior and relationships but that the effects were heterogeneous, with girls and academically more able children experiencing stronger effects. As a consequence, special needs education may have a fostering effect for some groups of individuals with mental disorders.

\subsection{The effect of educational qualifications}

Attaining an upper-secondary level of education is crucial for the employment prospects of all young adults (OECD 2010; European Agency for Development in Special Needs Education 2016). However, educational qualifications may be of particular importance in educational systems with high standardization. According to the typology developed by Allmendinger (1989), distinguishing between edu- 
cational systems with high and low stratification and standardization, Switzerland has a system with both high stratification and high standardization: after primary education, and again after lower-secondary education, individuals are selected into different educational tracks. Within these tracks the training is the same for everyone and the qualifications attained from each track are thus standardized. Standardized qualifications provide employers with knowledge about what to expect from a future employee. As a consequence, standardized systems allow a smoother transition from education to employment than other systems because young individuals do not have to repeatedly change jobs until they find a position that matches their qualifications.

In the context of individuals with mental disorders, two-year upper-secondary qualifications provided by the Swiss school system may be of particular interest as they offer a scheme that provides individuals with learning difficulties with additional support (SBFI 2014). In an analysis of the employment prospects of individuals completing different types of upper-secondary education, it has been shown that individuals completing a two-year qualification have lower chances of finding a job within six months than those with a three- or four-year qualification (Fitzli et al. 2016). Nevertheless, the differences are relatively small, with $75 \%$ of them being in employment against $83 \%$ for those with a three- or four-year qualification.

\subsection{Hypotheses}

Based on this discussion of the literature we have three competing hypotheses:

1. In comparison with educational trajectories and educational qualifications, diagnoses most strongly affect individuals' employment prospects. Following the theory of cumulative advantage/disadvantage (Dannefer 2003), individuals with an early onset of mental disorders are more strongly impeded in their employment prospects than individuals with a later onset. We therefore expect that individuals with behavioral and emotional disorders with onset occurring in childhood and adolescence are more negatively affected in their employment prospects than individuals with disorders of adult personality and behavior.

2. In comparison with diagnoses and educational qualifications, educational trajectories most strongly affect individuals' employment prospects. More precisely, individuals who attend special needs education are more likely to find a job than individuals who attend regular education. This hypothesis is based on the idea that educational institutions support individuals with mental disorders in remaining in school and attaining a qualification.

3. In comparison to diagnoses and educational trajectories, educational qualifications most strongly affect individuals' employment prospects. This expectation follows Allmendinger's (1989) theory stating that in educational systems with high standardization - such as Switzerland's educational system - educational 
qualifications are of preponderant importance to individuals' employment prospects.

\section{Method}

\subsection{Data}

The sample was identified based on the FSIO register. It consists of new disability pensioners and non-disability pensioners with psychiatric diagnoses who had applied for disability benefits prior to 2010 via a cantonal disability pension office in the French- or German-speaking regions of Switzerland. Inclusion criteria for the new disability pensioners were that they received their first disability pension due to a psychiatric diagnosis between 2010 and 2013, and were aged 18 to 29 at the time of the pension award. Inclusion criteria for the non-disability pensioners were that they had never received a disability pension; had received rehabilitation measures due to a psychiatric diagnosis between 2010 and 2011; were aged 18 to 29 when these rehabilitation measures were granted; and had received no additional support measures between 2012 and 2013. This two-year measures-free time-frame was selected to mitigate the potential for an individual selected as a non-disability pensioner to receive a disability pension for a psychiatric diagnosis in the future.

Samples of 400 new disability pensioners and 100 non-disability pensioners were obtained from the respective populations. The overall sample size had to be restricted to 500 individuals due to the resource- and time-consuming data collection process. From the sample four observations were dropped because there was no information available about individuals' education. For this reason, our final sample consists of 496 individuals.

For all individuals in the sample, data was obtained from individual case files. Five purpose-trained research assistants manually extracted information from the case files using a coding scheme and an extensive codebook developed in agreement with experts from the fields of psychiatry, psychology, education, and the FSIO. This coded information was anonymized and constitutes our final dataset. An in-depth description of the data collection is provided in a research report mandated by the FSIO (Baer et al. 2015).

\subsection{Measures}

\subsubsection{Dependent variable}

Our dependent variable is current employment and is measured dichotomously, distinguishing between being currently employed and being not currently employed. We use currently employed instead of ever been employed as the dependent variable to ensure our results are not biased in favor of individuals with an onset of mental 
disorder in adulthood. A more detailed description of this measure is provided in Table A. 1 in the Appendix.

\subsubsection{Independent variables}

Our measure for mental disorders is based on the International Classification of Diseases ICD-10 (WHO 1992) and distinguishes between eight different diagnoses. Educational trajectories consist in a typology created by means of cluster analysis. Within the sequences we distinguish between twelve different states. With respect to highest qualification completed, we distinguish between eight different levels following the International Standard Classification of Education (ISCED 1997). A more detailed description of these measures is provided in Table A.1 in the Appendix. Finally, we use age as a continuous variable and nationality, distinguishing between Swiss and other nationalities. Further demographic and socio-economic characteristics such as sex or socio-economic background were not available in the dataset.

\subsection{Analytical strategies}

To create the educational trajectories we used sequence analysis (Abbott 1995). Sequence methods aim at extracting simplified workable information from sequential datasets by summarizing this information. This analysis was carried out using the TraMineR package of the statistical software $R$ (Gabadinho et al. 2011). Using this method we examined the chronological order of states of individuals' trajectories and how similar all possible pairs of individual sequences are. This analysis resulted in a pairwise distance matrix representing the similarity of individual trajectories. The distance was measured on the one hand by means of optimal matching analysis and on the other by using the dynamic Hamming distance that specifies the timedependent substitution costs based on time-point specific transition probabilities between two sequence states (Macindoe and Abbott 2004; Lesnard 2010). In a next step we conducted a cluster analysis, specifically Ward cluster analysis, which creates homogeneous groups of sequences. This method allows categorizing the sequential patterns into a limited number of groups (Gabadinho et al. 2011).

We then carried out regression analyses, more precisely binary logistic regression analyses, using the clusters from the cluster analysis as one of several independent variables. This allowed us to examine how each cluster membership is related to covariates. We computed three models, a first model where we entered only the diagnoses of mental disorder, a second model, where we added educational trajectories and a third model where we added educational controlling in all models for age and nationality.

The analysis of the effect of educational trajectories on employment prospects is affected by endogeneity (Card 1999). Finding an association between educational trajectories and employment prospects does not guarantee that the trajectory caused the outcome. In fact, it is possible that this finding is explained by a third factor, 
for instance socio-economic background that explains both attending a specific educational trajectory and employment prospects. Additionally, reverse causality may take place, i. e. the type of trajectory or the outcomes may affect individuals' mental health due to health behaviors or the experience of stress (Ettner 2000).

\section{Results}

\subsection{Descriptive results}

The mean age of our sample is 22.3 years and about $85 \%$ are of Swiss nationality. With respect to their highest qualification obtained, the largest share of individuals has a lower-secondary qualification $(\mathrm{n}=198,41 \%)$ or an upper-secondary qualification $(\mathrm{n}=167,53 \%)$. In comparison to the general Swiss population aged 25-64, where in 2013 about $14 \%$ had a lower-secondary qualification, individuals in our sample were much more likely to complete a lower secondary education (BFS 2016). ${ }^{3}$ The share of individuals with an upper-secondary qualification in our sample is similar to the general population where it is $49 \%$. However, the share of individuals in our sample who have completed only a two-year upper-secondary education is substantially higher than in the average cohorts finishing education (BFS 2015). With respect to diagnoses, the largest shares of individuals in our sample have F7 (22\%), F6 (21\%) and F2 (18\%) diagnoses. With respect to individuals' employment situation, we find that about $35 \%$ of our sample are currently employed whereas $65 \%$ are currently not employed. The share of employed individuals in our sample is thus low in comparison to that of the general Swiss population aged 15-64 (82\%) (OECD Statistics 2013). Among those who are currently employed, about half are in sheltered employment. An overview of the descriptive statistics is provided in Table A.2 in the Appendix.

With respect to the educational trajectories, we created five clusters from the individual sequences - resulting in five types of sequences. Figure 1 presents the aggregated sequences, sorted by states, within the five types. The first type $(n=236,49 \%)$ primarily consists of individuals who attended regular education throughout their entire educational career (henceforth RE1). About $40 \%$ of the individuals in RE1 have completed a VET program with graduation while about 30\% did not complete their VET program and about $10 \%$ dropped out of school. The second type $(n=43,9 \%)$ comprises changes from a first to a second regular education (RE2). In RE2 the rate of completion of vocational education is higher than in RE1 at about $80 \%$. Individuals in the third type $(n=78,16 \%)$ usually started in

3 This comparison has the limitation that our sample is similar to a cohort, consisting of individuals aged under 30 at the moment of the measurement. The general population in contrast encompasses individuals up to age 64. As the share of individuals attaining higher qualifications increases with younger cohorts, our result indicates that our sample is particularly disadvantaged (BFS 2016). 
Figure 1 Five types of educational trajectories (distribution of states) Type $1(n=236)$ Type $2(n=43)$

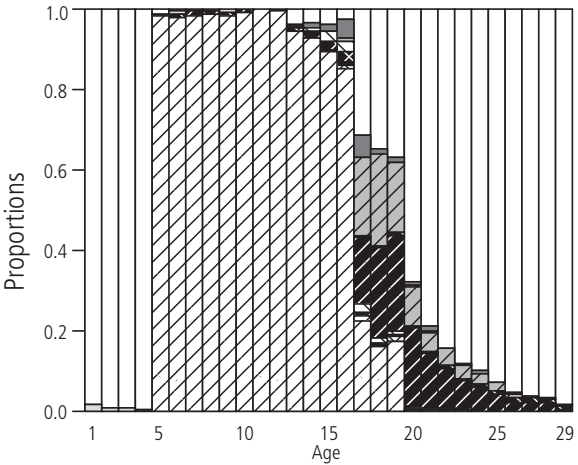

Type $3(n=76)$

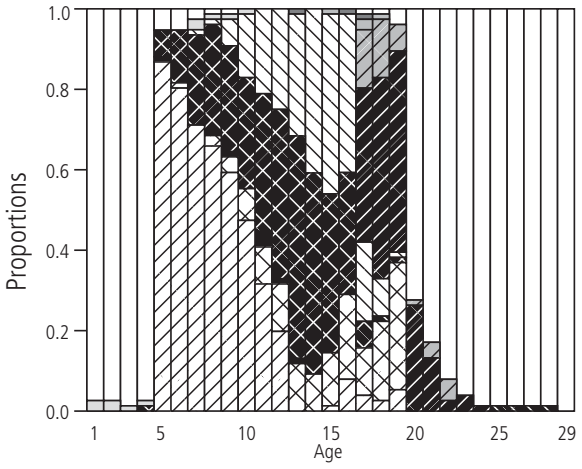

Type $5(n=23)$

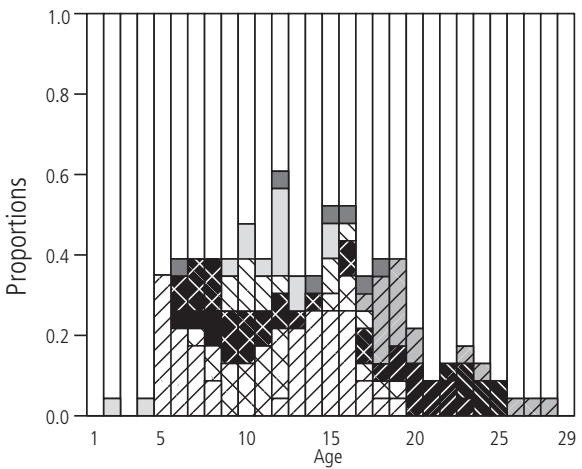

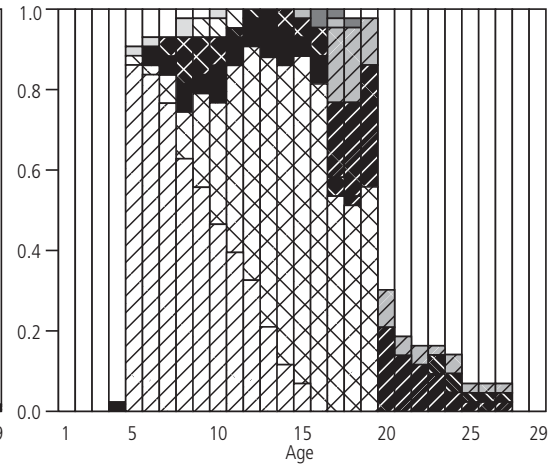

Type $4(n=118)$

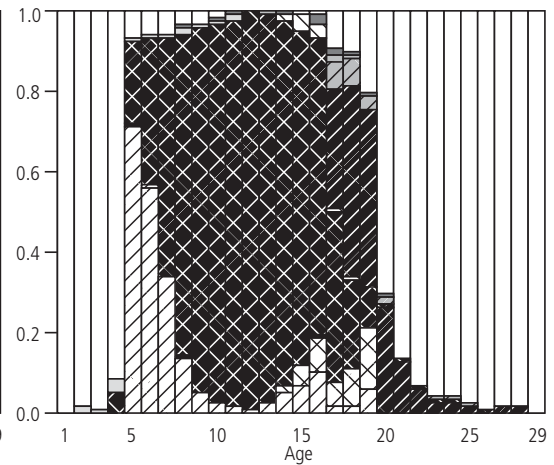

Legend

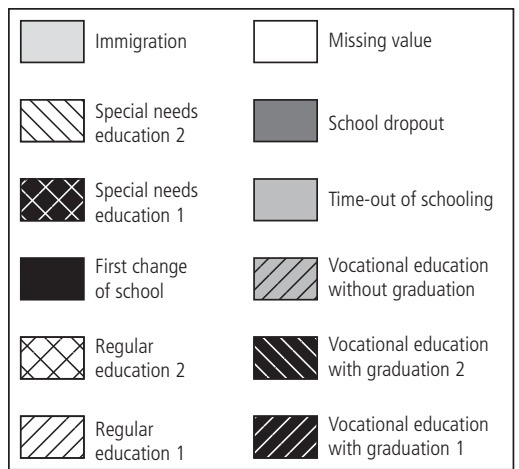

Note: The figures indicate trajectories from age 1 through age 29. $N$ Type 1 (RE1)=236, N Type 2 (RE2) =43, N Type 3 (EC)=76, N Type 4 $(S N E)=118, N$ Type $5(E I)=23$. 
regular education but eventually changed school to regular or special needs education or both (EC). EC is characterized by multiple changes of school. The fourth type $(n=118,24 \%)$ includes individuals who spent most of their educational trajectory in special needs education (SNE). Individuals in SNS are characterized by a high level of completion of vocational education with about $80 \%$. Finally, type five $(n=23,5 \%)$ comprises individuals who interrupted their educational careers either at one or multiple points (EI). The share of individuals in this type who have completed any type of education is low.

\subsection{Regression results}

Model 1 in Table 1 presents the association between ICD-10 diagnosis and individuals' chances of being currently employed, controlling for age and nationality. Not surprisingly, age has a statistically significant but small effect. Individuals of Swiss nationality are significantly and substantially more likely to be currently employed than individuals of other nationalities. With respect to diagnosis, our analysis shows that compared to the reference category behavioral and emotional

Table 1

Logistic regression for being currently employed

\begin{tabular}{|c|c|c|c|c|c|c|}
\hline \multirow[t]{2}{*}{ Variables } & \multicolumn{2}{|c|}{ Model 1} & \multicolumn{2}{|c|}{ Model 2} & \multicolumn{2}{|c|}{ Model 3} \\
\hline & Coef. & $\mathrm{SE}$ & Coef. & SE & Coef. & SE \\
\hline Age & $0.010^{* *}$ & 0.007 & $0.020^{* * *}$ & 0.007 & 0.008 & 0.008 \\
\hline \multicolumn{7}{|l|}{$\begin{array}{l}\text { Nationality } \\
\text { (ref.: Other nationalities) }\end{array}$} \\
\hline Switzerland & $0.180^{* * *}$ & 0.050 & $0.170^{* * *}$ & 0.060 & $0.180^{* * *}$ & 0.060 \\
\hline \multicolumn{7}{|l|}{ ICD-10 Diagnosis (ref.: F9) } \\
\hline FO & 0.002 & 0.130 & -0.010 & 0.130 & -0.010 & 0.130 \\
\hline $\mathrm{F} 2$ & -0.140 & 0.080 & -0.120 & 0.080 & -0.100 & 0.080 \\
\hline F3 & $-0.180^{*}$ & 0.100 & -0.160 & 0.100 & $-0.210^{* *}$ & 0.100 \\
\hline $\mathrm{F} 4$ or F5 & $-0.180^{*}$ & 0.100 & -0.170 & 0.100 & -0.160 & 0.100 \\
\hline F6 & $-0.170^{*}$ & 0.080 & $-0.160^{*}$ & 0.080 & $-0.140^{*}$ & 0.080 \\
\hline F7 & 0.120 & 0.070 & 0.090 & 0.080 & 0.070 & 0.070 \\
\hline F8 & 0.050 & 0.080 & 0.020 & 0.080 & -0.004 & 0.080 \\
\hline \multicolumn{7}{|l|}{ Educational trajectories (ref.: RE1) } \\
\hline RE2 & & & -0.010 & 0.070 & -0.020 & 0.070 \\
\hline EC & & & $0.110^{*}$ & 0.060 & 0.100 & 0.060 \\
\hline SNE & & & $0.120^{* *}$ & 0.050 & $0.120^{* *}$ & 0.050 \\
\hline El & & & -0.050 & 0.100 & 0.070 & 0.100 \\
\hline Highest qualification completed & & & & & $0.100 * * *$ & 0.020 \\
\hline Constant/Intercept & -0.140 & 0.160 & -0.260 & 0.180 & -0.390 & 0.180 \\
\hline N & \multicolumn{2}{|c|}{496} & \multicolumn{2}{|c|}{496} & \multicolumn{2}{|c|}{496} \\
\hline
\end{tabular}

Note: Significance levels: $p \leq 0.001^{* * *}, p \leq 0.01^{* *}, p \leq 0.05^{*}$. The dependent variable distinguishes between (i) being currently employed $(N=171)$ and (ii) not being currently employed $(N=325)$. 
disorders with onset occurring in childhood and adolescence (F9), individuals with mood (affective) disorders (F3), neurotic, stress-related and somatoform disorders or behavioral syndromes associated with psychological disturbances and physical factors (F4 or F5) and disorders of adult personality and behavior (F6) have lower employment prospects.

In Model 2 we add the educational trajectories and find that individuals who experienced educational change (EC) or special needs education (SNE) trajectories are significantly and substantially more likely to be currently employed than individuals in type regular education 1 (RE1). Model 2 also shows that individuals in regular education 2 (RE2) and educational interruption (EI) trajectories have lower chances of being currently employed than individuals in RE1 trajectories, although the effect is small. However, in terms of diagnosis, we no longer find statistically significant effects except for F6. This step provides us with similar effects for age and nationality as Model 1.

In Model 3 we add the highest qualification obtained and find that the higher the qualification, the higher the likelihood of being currently employed. With respect to educational trajectories, we find a strongly positive significant effect of SNE as compared to the reference category RE1. The effect of EC and EI are positive but not statistically significant. With respect to diagnosis we find a strongly negative significant effect of F3 and F6. Whereas age loses statistical significance, we still observe a large and statistically significant effect of nationality on individuals' chances of being currently employed.

\section{Discussion}

This paper examines how individuals' type of diagnosis, their educational trajectories and educational qualifications affect their employment prospects. We tested three competing hypotheses, each of which stated the relative importance of these three factors. Overall, our analyses showed that all of them contribute to the explanation of employment prospects. Yet, the type of diagnosis loses predictive power if educational trajectories and qualifications are included into the analysis; educational trajectories lose predictive power if educational qualifications are included. It seems however remarkable that educational trajectories still remain an important factor even if educational qualifications are included, indicating that attending special needs education per se provided individuals with better employment prospects.

In contrast to our first hypothesis on cumulative advantages/disadvantages, we found that individuals with diagnoses that typically have their onset in late adolescence or adulthood have weaker employment prospects than individuals with diagnoses that typically have their onset in childhood and early adolescence. Yet, this pattern has not been observed for individuals with a diagnosis of schizophrenia 
with a typically late onset. This is in line with an earlier analysis of the same dataset that showed that individuals with schizophrenia receive disability pensions earlier than individuals with other types of diagnoses (Baer et al. 2015). As we do not have information about the effective age of onset of mental disorder, the assumption that individuals with an early onset have better employment prospects remains an interpretation.

Our study contributes to the discussion in the literature about whether so-called externalizing problems (which include F6, disorders of adult personality and behavior) or internalizing problems (which include F3, affective [mood] disorders) affect individuals' labor market status more strongly. In contrast to an earlier study from the Netherlands that found significant effects only for externalizing problems, we showed effects for both categories of problems (Veldman et al. 2015). A potential explanation of this finding is that our sample includes individuals up to age 29 when internalizing problems may be more strongly developed than in the sample of the Dutch study that included individuals only up to age 19. Moreover, the importance of F6 and F3 for individuals' employment prospects may be the work impairment associated with these disorders and a lack of early detection and targeted vocational interventions for individuals with these disorders (McIntyre et al. 2011).

We find support for our second hypothesis, assuming that special needs education acts as a protection from educational interruptions and leads to better employment prospects. We find indeed that individuals who attended special needs education either from early on or at least for a substantial part of their educational trajectory have better prospects of being employed in young adulthood. Taken together, these findings seem to suggest that individuals with an early onset of mental disorder who enter special needs education early on have the relatively best employment prospects. A possible explanation of this finding is that individuals who spent all or most of their educational career in special needs education often are employed in sheltered employment which may be attained even in the presence of impairments.

However, our cluster analysis also showed that individuals in trajectories involving special needs education have higher rates of completing VET programs than individuals in trajectories involving foremost regular education. This finding corroborates the assumption that special needs education provides support for individuals with mental disorders to complete their educational trajectory and avoid school dropout (Downes 2011). In fact, it has been argued that institutions such as the school system, the family and the labor market provide adolescents with opportunities and constraints, contributing to the establishment of normatively appropriate ways of behaving (Breen and Buchmann 2002). In German-speaking regions such as parts of Switzerland for instance, comparatively strong parental control and well-demarcated pathways into adulthood may provide adolescents with a relatively clearly defined set of social norms. As a consequence, special needs education may 
attenuate the potential negative effects of mental disorders on educational and occupational outcomes.

Moreover, our analyses show that children and adolescents who attend regular school are more likely to drop out of school or leave the parental home early. A potential reason may be the existence of testing regimes that increases individuals' risks to drop out of school because of not passing the tests. This risk exists for all individuals but may be particularly high for those with special needs (Smith and Douglas 2014). Dropping out of school may in turn expose individuals to a higher risk of deviance (Merton 1959; Cohen 1965). Entering a regular educational trajectory may thus not only prevent individuals with special needs from attaining a qualification but also negatively affect their social integration, which in the long run may reduce their employment prospects.

Our finding that higher educational qualifications provide individuals with better employment prospects confirms our third hypothesis. It is in line with Allmendinger's (1989) theory on the link between educational systems and labor market outcomes suggesting that in highly standardized educational systems, such as Switzerland, qualifications provide employers with a guarantee of candidates' skills.

Overall, we find mixed evidence for a mechanism of CAD to be acting (Dannefer 2003). On the one hand, our analysis points to a negative effect of school dropout and leaving school without qualification on employment prospects which provides support to the CAD theory. On the other hand, we observe that individuals who mainly attended regular education - and thus were probably not disadvantaged in terms of mental disorders in early childhood - were more likely to drop out of school. Moreover, we find that these individuals were less likely to be employed at the moment of the measurement. At the same time, vulnerability of individuals with an early onset of mental disorders is buffered by an educational system that offer tracks for individuals with special needs. The existence of social institutions and companies who offer sheltered vocational training programs and sheltered employment may absorb individuals who otherwise would have bleak labor-market prospects. However, it seems that the labor market does not offer them the degree of support that they may need to pursue a standard occupational career in non-sheltered employment, which may hamper their social integration and financial independence. In line with recommendations by the OECD, future efforts may involve occupational counseling services that provide young adults with mental disorders with the necessary support to manage the transition to employment (OECD 2015).

Finally, we also found that individuals with Swiss nationality have better employment prospects than individuals with other nationalities. This is in line with earlier research: an experimental study simulated the job search of young adults who had completed an upper-secondary education in Switzerland (Fibbi et al. 2006). The authors find that individuals with a family name indicating an immigrant 
background from non-European Union countries had substantially lower chances of being invited to a job interview.

Our study draws on an innovative method to explain the educational and occupational attainment of young adults with mental disorders. By considering not only educational qualifications but also the totality of the educational trajectory, we receive a more in-depth picture of potential mechanisms at work. Using longitudinal data and sequence analysis also allows us to differentiate between educational trajectories involving educational changes (EC) and special needs education (SNE), both of whose members have attended some special needs education, but, for members of EC, only during parts of their careers. Individuals who experienced an EC type of educational trajectory seem to be similar to those who have an SNE type of trajectory but are slightly more disadvantaged.

The method used, however, also presents some limitations. Cluster analysis is empirically led, meaning that the clusters are constructed by means of an algorithm which is not created based on theoretical considerations but based on the data at hand. Moreover, cluster analysis is probably subject to selection bias with not only observed but also unobserved characteristics driving the selection. In this scenario, we would expect that individuals with a later onset of mental illness are channeled into both regular educational trajectories and better employment prospects. However, having spent most of one's educational trajectory in regular education is not accompanied by advantages in terms of employment prospects. This indicates that selection effects do not (completely) explain the adherence to an educational trajectory.

Another limitation is possibly given by restrictions of our data. First, our sample is highly selective in the sense that it includes only individuals with mental disorders who have applied for disability benefits. As a consequence, our results are not generalizable to individuals who have never claimed disability benefits. Secondly, comorbidities were not assessed and information about the severity of the mental disorders was not available in our data. As severity is an important determinant of the dimension of individuals' constraints in daily life, it would have contributed to a more detailed understanding of the mechanisms determining individuals' employment prospects (OECD 2012). However, research shows that individuals with mild mental disorders are also negatively affected in terms of their labor market outcomes (Birnbaum et al. 2010). Thirdly, earlier research highlights the importance of individuals' socio-economic background for their educational attainment (Boone and Van Houtte 2013). As the respective information was not available in our dataset, we were not able to examine the effect of this factor in the present study. Finally, we do not know which type of special needs education individuals attended. Different outcomes would probably be attained if we were able to compare individuals who attended regular education with special needs interventions (integrated schooling) and individuals who attended special needs schools. 
As integrated schooling has been institutionalized in Switzerland since the signature of the United Nations Convention on the Rights of Persons with Disabilities in 2014, research including these different types of special needs education will be possible in the future. Other future research directions involve a more detailed examination of the types of jobs - including job quality and wages - in which young adults with mental disorders are hired.

\section{Conclusion}

In comparison with the average population, young adults with mental disorders are less likely to attain educational credentials and to participate in the labor market. However, their employment prospects vary with respect to their diagnoses, educational trajectories and educational qualifications. Individuals with mental disorders that typically have an onset in early childhood, those who experience educational trajectories including special needs education and those attaining higher levels of qualifications are more likely to be employed in early adulthood - although often in sheltered jobs. This may imply that individuals with an early onset of mental disorder tend to attend special needs education, which prevents them from interrupting their educational trajectories or leaving education without qualification but leads them into sheltered vocational education programs. Receiving support and guidance is likely to enable them to attain higher levels of education than if they would have attended regular school. This increases their employment prospects. As a consequence, mechanisms such as cumulative disadvantages that reinforce early adversities may be attenuated. In contrast, individuals with a late onset of mental disorder probably tend to remain in regular education and experience a higher risk of not finishing education. We thus conclude that these individuals are the most vulnerable group of young adults with mental disorders.

\section{$7 \quad$ References}

Abbott, Andrew. 1995. Sequence Analysis: New Methods for Old Ideas. Annual Review of Sociology 21: 93-113.

Alexander, Karl L., Doris R. Entwisle, and Carrie S. Horsey. 1997. From First Grade Forward: Early Foundations of High School Dropout. Sociology of Education 70(2): 87-107.

Allmendinger, Jutta. 1989. Educational Systems and Labor Market Outcomes. European Sociological Review 5(3): 231-250.

Andersen, Jorgen Goul. 2002. Coping With Long-Term Unemployment: Economic Security, Labour Market Integration and Well-Being. Results From a Danish Panel Study, 1994-1999. International Journal of Social Welfare 11: 178-190. 
Baer, Niklas, Szilvia Altwicker-Hámori, Sibylle Juvalta, Ulrich Frick, and Peter Rüesch. 2015. Profile von Jungen IV-Neurentenbeziehenden mit psychischen Krankheiten. Forschungsbericht Nr. 19/15. Bern: Bundesamt für Sozialversicherungen (BSV).

Baer, Niklas, Ulrich Frick, and Tanja Fasel. 2009. Dossieranalyse der Invalidisierungen aus psychischen Gründen. Typologisierung der Personen, ihrer Erkrankungen, Belastungen und Berentungsverläufe. Forschungsbericht Nr. 6/09. Bern: Bundesamt für Sozialversicherungen (BSV).

BFS. 2016. Gleichstellung von Menschen mit Behinderung - Bildung - obligatorische Schule. https://www.bfs.admin.ch/bfs/de/home/statistiken/wirtschaftliche-soziale-situation-bevoelkerung/ gleichstellung-menschen-behinderungen/bildung/obligatorische-schule.html (31.08.2017).

BFS. 2015. Übergänge und Verläufe auf der Sekundarstufe II. Neuchâtel: Bundesamt für Statistik (BFS).

BFS. 2010. Demos Newsletter: Informationen aus der Demographie. Neuchâtel: Bundesamt für Statistik (BFS).

Birnbaum, Howard G., Ronald C. Kessler, David Kelley, Rym Ben-Hamadi, Vijay N. Joish, and Paul E. Greenberg. 2010. Employer Burden of Mild, Moderate, and Severe Major Depressive Disorder: Mental Health Services Utilization and Costs, and Work Performance. Depression and Anxiety 27(1): 78-89.

Boone, Simon and Mieke Van Houtte. 2013. In Search of the Mechanisms Conducive to Class Differentials in Educational Choice: A Mixed Method Research. Sociological Review 61(3): 549-572.

Breen, Richard and Marlis Buchmann. 2002. Institutional Variation and the Position of Young People: A Comparative Perspective. The Annals of the American Academy of Political and Social Science 580: 288-305.

Breslau, Joshua, Michael Lane, Nancy Sampson, and Ronald C. Kessler. 2008. Mental Disorders and Subsequent Educational Attainment in a US National Sample. Journal of Psychiatric Research 42(9): 708-716.

Burchardt, Tania. 2005. The Education and Employment of Disabled Young People: Frustrated Ambition. Bristol UK: The Policy Press.

Card, David. 1999. The Causal Effect of Education on Earnings. Pp. 1801-1863 in Handbook of Labor Economics, Vol. 3, edited by Orley Ashenfelter and David Card. North Holland: Elsevier.

Chatterji, Pinka, Margarita Alegria, and David Takeuchi. 2011. Psychiatric Disorders and Labor Market Outcomes: Evidence From the National Comorbidity Survey-Replication. Journal of Health Economics 30(5): 858-868.

Cohen, Albert K. 1965. The Sociology of the Deviant Act: Anomie Theory and Beyond. American Sociological Review 30(1): 5-14.

Cook, Judith A. and Lisa Razzano. 2000. Vocational Rehabilitation for Persons With Schizophrenia: Recent Research and Implications for Practice. Schizophrenia Bulletin 26(1): 87-103.

Dannefer, Dale. 2003. Cumulative Advantage/Disadvantage and the Life Course: Cross-Fertilizing Age and Social Science Theory. Journal of Gerontology: Social Sciences 58(6): 327-337.

Downes, Paul. 2011. The Neglected Shadow: European Perspectives on Emotional Supports for Early School Leaving Prevention. The International Journal of Emotional Education 3(2): 3-36.

Ettner, Susan L. 2000. The Relationship Between Labor Market Outcomes and Physical and Mental Health: Exogenous Human Capital or Endogenous Health Production? The Economics of Disability 13: $1-31$.

European Agency for Development in Special Needs Education. 2016. Early School Leaving and Learners With Disabilities and/or Special Educational Needs: A Review of the Research Evidence Focusing on Europe. Odense, Denmark.

Fibbi, Rosita, Mathias Lerch, and Philippe Wanner. 2006. Unemployment and Discrimination Against Youth of Immigrant Origin in Switzerland: When the Name Makes the Difference Children of Immigrants. Journal of International Migration and Integration 7(3): 351-366. 
Fitzli, Dora, Max Grütter, Marie-Christina Fontana, Kathrin Koebel, and Simon Bock. 2016. Evaluation der Arbeitsmarktsituation und Weiterbildungsperspektive von Absolventen und Absolventinnen mit eidgenössischem Berufsattest (EBA). Bern: Staatssekretariat für Bildung, Forschung und Innovation (SBFI).

Gabadinho, Alexis, Gilbert Ritschard, Nicolas Séverin Mueller, and Matthias Studer. 2011. Analyzing and Visualizing State Sequences in R With TraMineR. Journal of Statistical Software 40(4): 1-37.

Gallie, Duncan and Serge Paugam. 2002. Social Precarity and Social Integration. Brussels: European Commission Directorate-General for Employment, Industrial Relations and Social Affairs.

Harnois, Gaston and Phyllis Gabriel. 2000. Mental Health and Work: Impact, Issues and Good Practices. Geneva: World Health Organization (WHO).

Holzner, Bernhard, Georg Kemmler, and Ullrich Meise. 1998. The Impact of Work-Related Rehabilitation on the Quality of Life of Patients With Schizophrenia. Social Psychiatry and Psychiatric Epidemiology 33(12): 624-631.

Humphrey, Neil, Ann Lendrum, Alexandra Barlow, Michael Wigelsworth, and Garry Squires. 2013. Achievement for All: Improving Psychosocial Outcomes for Students With Special Educational Needs and Disabilities. Research in Developmental Disabilities 34(4): 1210-1225.

ISCED. 1997. International Classification of Education. Paris: UNESCO.

Jackson, Margot I. 2015. Cumulative Inequality in Child Health and Academic Achievement. Journal of Health and Social Behavior 56(2): 262-280.

Jahoda, Marie. 1981. Work, Employment, and Unemployment: Values, Theories, and Approaches in Social Research. American Psychologist 36(2): 184-191.

Janosz, Michel, Isabelle Archambault, Julien Morizot, and Linda S. Pagani. 2008. School Engagement Trajectories and Their Differential Predictive Relations to Dropout. Journal of Social Issues 64(1): $21-40$.

Kern, Lee, Steven W. Evans, Timothy J. Lewis. 2015. CARS Comprehensive Intervention for Secondary Students With Emotional and Behavioral Problems. Journal of Emotional and Behavioral Disorders 23(4): 195-205.

Lesnard, Laurent. 2010. Setting Cost in Optimal Matching to Uncover Contemporaneous Socio-Temporal Patterns. Sociological Methods \& Research 38(3): 389-419.

Levinson, Daphna, Lakoma, Matthew D., Petukhova, Maria, Schoenbaum, Michael, Zaslavsky, Alan M., Angermeyer, Matthias, Borges, Guilherme, Bruffaerts, Ronny, de Girolamo, Giovanni, de Graaf, Ron, Gureje, Oye, Haro, Josep Maria, Hu, Chiyi, Karam, Aimee N., Kawakami, Norito, Lee, Sing, Lepine, Jean-Pierre, Browne, Mark Oakley, Okoliyski, Michail, Posada-Villa, José, Sagar, Rajesh, Viana, Maria Carmen, Williams, David R., Kessler, Ronald C. 2010. Associations of Serious Mental Illness With Earnings: Results From the WHO World Mental Health Surveys. British Journal of Psychiatry 197(2): 114-121.

Macindoe, Heather and Andrew Abbott. 2004. Sequence Analysis and Optimal Matching Techniques for Social Science Data. Pp. 387-406 in Handbook of Data Analysis, edited by Melissa Hardy and Alan Bryman. Los Angeles/London: SAGE.

McIntyre, Roger S., Samantha Liauw, and Valerie H. Taylor. 2011. Depression in the Workforce: the Intermediary Effect of Comorbidity. Journal of Affective Disorders, 128(Suppl 1): 29-36.

McLeod, Jane D. and Elbert P. Almazan. 2003. Connections Between Childhood and Adulthood. Pp. 391-411 in Handbook of the Life Course, edited by Jeylan T. Mortimer and Michael J. Shanahan. New York: Kluwer Academic/Plenum Publishers.

Merton, Robert K. 1959. Social Conformity, Deviation, and Opportunity Structures: A Comment on the Contributions of Dubin and Cloward. American Sociological Review 24(2): 177-189.

OECD. 2015. Fit Mind, Fit Job. Paris: OECD Publishing. 
OECD. 2014. Making Mental Health Count. The Social and Economic Costs of Neglecting Mental Health Care. OECD Health Policy Studies. Paris: OECD Publishing.

OECD. 2012. Sick on the Job? Myths and Realities About Mental Health and Work, Mental Health and Work. Paris: OECD Publishing.

OECD. 2010. Off to a Good Start? Jobs for Youth. Paris: OECD Publishing.

OECD Statistics. 2013. http://stats.oecd.org/ (31.08.2017).

Patel, Vikram, Lund, Crick, Hatherill, Sean, Plagerson, Sophie, Corrigall, Joanne, Funk, Michelle, Flisher, Alan J. 2010. Mental Disorders: Equity and Social Determinants. Pp. 115-34 in Equity, Social Determinants and Public Health Programmes, edited by Erik Blas and Anand S. Kurup. Geneva: World Health Organization (WHO).

Pescosolido, Bernice A., Martin, Jack K., Long, J. Scott, Medina, Tait R., Phelan, Jo C., Link, Bruce G. 2010. "A Disease Like Any Other"? A Decade of Change in Public Reactions to Schizophrenia, Depression, and Alcohol Dependence. The American Journal of Psychiatry 167(11): 1321-1330.

Ranci, Costanzo. 2010. Social Vulnerability in Europe: The New Configuration of Social Risks. New York: Palgrave Macmillan.

Reavley, Nicola J. and Anthony F. Jorm. 2012. Public Recognition of Mental Disorders and Beliefs About Treatment: Changes in Australia Over 16 Years. The British Journal of Psychiatry 200(5): 419-425.

Richter, Dirk and Klaus Berger. 2013. Are Mental Disorders Increasing? Update of a Systematic Review on Repeated Cross-Sectional Studies. Psychiatrische Praxis 40: 176-182.

Rüesch, Peter, Jeanine Graf, Peter C. Meyer, Wulf Rössler, and Daniel Hell. 2004. Occupation, Social Support and Quality of Life in Persons With Schizophrenic or Affective Disorders. Social Psychiatry and Psychiatric Epidemiology 39: 686-694.

Rüesch, Peter, Peter C. Meyer, Jeanine Graf, and Daniel Hell. 2002. Beschäftigungslage von Schizophrenieund Affektkranken. Psychiatrische Praxis 29: 68-75.

SBFI. 2016. Vocational and Professional Education and Training in Switzerland. Facts and Figures 2016. Bern: Staatssekretariat für Bildung, Forschung und Innovation (SBFI).

SBFI. 2014. Zweijährige berufliche Grundbildung mit eidgenössischem Berufsattest. Leitfaden. Bern: Staatssekretariat für Bildung, Forschung und Innovation (SBFI).

Shavit, Yossi and Walter Müller. 2000. Vocational Secondary Education. European Societies 2(1): 29-50.

SKBF. 2014. Bildungsbericht 2014. Aarau: Schweizerische Koordinationsstelle für Bildungsforschung.

Smith, Emma and Graeme Douglas. 2014. Special Educational Needs, Disability and School Accountability: An International Perspective. International Journal of Inclusive Education 18(5): 443-458.

Spini, Dario, Laura Bernardi, and Michel Oris. 2017. Toward a Life Course Framework for Studying Vulnerability. Research in Human Development 14(1): 5-25.

Spini, Dario, Doris Hanappi, Laura Bernardi, Michel Oris, and Jean-François Bickel. 2013. Vulnerability Across the Life Course: A Theoretical Framework and Research Directions. LIVES Working Papers 27(27): 1-38.

Turney, Kristin and Sara McLanahan. 2015. The Academic Consequences of Early Childhood Problem Behaviors. Social Science Research 54: 131-145.

United Nations. 2008. Übereinkommen über die Rechte von Menschen mit Behinderungen (Convention on the Rights of Persons with Disabilities - CRPD). Geneva: United Nations.

Veldman, Karin, Sijmen A. Reijneveld, Josue Almansa Ortiz, Frank C. Verhulst, and Ute Bültmann. 2015. Mental Health Trajectories From Childhood to Young Adulthood Affect the Educational and Employment Status of Young Adults: Results From the TRAILS Study. Journal of Epidemiology \& Community Health 69(6): 588-593. 
WHO. 1992. The ICD-10 Classification of Mental and Behavioural Disorders: Clinical Descriptions and Diagnostic Guidelines. Genève: World Health Organization (WHO).

\section{Appendix}

Table A.1 Description of the measures

\begin{tabular}{|c|c|}
\hline Measure & Description \\
\hline \multicolumn{2}{|l|}{ Employment situation } \\
\hline Currently employed & $\begin{array}{l}\text { Employed in permanent jobs, fixed-term jobs, sheltered jobs, } \\
\text { non-sheltered jobs and internships at the moment of the } \\
\text { measurement. Vocational education is not included in this } \\
\text { definition. }\end{array}$ \\
\hline Not currently employed & $\begin{array}{l}\text { Individuals who have been employed earlier but not at the } \\
\text { moment of the measurement of the variable are defined as not } \\
\text { currently employed. This category also includes individuals who } \\
\text { have never been employed. }\end{array}$ \\
\hline \multicolumn{2}{|l|}{ ICD-10 Diagnoses } \\
\hline F0 & $\begin{array}{l}\text { Organic, including symptomatic mental disorders, e. g. organic } \\
\text { anxiety disorder }\end{array}$ \\
\hline F1 & $\begin{array}{l}\text { Mental and behavioral disorders due to psychoactive sub- } \\
\text { stance use. (This diagnosis was excluded from the sample due } \\
\text { to the decision of the FSIO) }\end{array}$ \\
\hline $\mathrm{F} 2$ & $\begin{array}{l}\text { Schizophrenia, schizotypal and delusional disorders, e.g. } \\
\text { schizophrenia }\end{array}$ \\
\hline F3 & Mood (affective) disorders, e.g. depressive episode \\
\hline F4 & $\begin{array}{l}\text { Neurotic, stress-related and somatoform disorders, e.g. pho- } \\
\text { bic anxiety disorder. (F4 and F5 were taken together in one } \\
\text { category because of the small number of observations with F5 } \\
\text { diagnosis.) }\end{array}$ \\
\hline F5 & $\begin{array}{l}\text { Behavioral syndromes associated with physiological distur- } \\
\text { bances and physical factors, e. g. eating disorder (F4 and F5 } \\
\text { were taken together in one category because of the small } \\
\text { number of observations with F5 diagnosis.) }\end{array}$ \\
\hline F6 & $\begin{array}{l}\text { Disorders of adult personality and behavior, e. g. paranoid } \\
\text { personality disorder. }\end{array}$ \\
\hline F7 & Mental retardation, e. g. mild mental retardation \\
\hline F8 & $\begin{array}{l}\text { Disorders of psychological development, e.g. specific speech } \\
\text { articulation disorder }\end{array}$ \\
\hline F9 & $\begin{array}{l}\text { Behavioral and emotional disorders with onset usually } \\
\text { occurring in childhood and adolescence, e. g. attention-deficit } \\
\text { hyperactivity disorder }\end{array}$ \\
\hline
\end{tabular}


Continuation of table A. 1.

\begin{tabular}{|c|c|}
\hline Measure & Description \\
\hline \multicolumn{2}{|l|}{ States in educational trajectories } \\
\hline Regular education 1 & First regular school attended \\
\hline Regular education 2 & $\begin{array}{l}\text { School individuals attend who have changed school to another } \\
\text { regular school }\end{array}$ \\
\hline Special needs education 1 & $\begin{array}{l}\text { First special needs school attended. Individuals may have } \\
\text { changed to the special needs school coming from a regular } \\
\text { school or started their educational career with a special needs } \\
\text { school }\end{array}$ \\
\hline Special needs education 2 & $\begin{array}{l}\text { Special needs school individuals attend who have changed } \\
\text { school to another special needs school }\end{array}$ \\
\hline Immigration & $\begin{array}{l}\text { Experienced an immigration from other countries before or } \\
\text { during their educational career }\end{array}$ \\
\hline Vocational education with graduation 1 & First VET that led to the acquisition of a qualification \\
\hline Vocational education with graduation 2 & Second VET that led to the acquisition of a qualification \\
\hline Vocational education without graduation & $\begin{array}{l}\text { Participation in a VET program without acquiring a qualifica- } \\
\text { tion }\end{array}$ \\
\hline Time-out & $\begin{array}{l}\text { Limited period during which individuals were excluded from } \\
\text { school by authorities }\end{array}$ \\
\hline Dropout & Definitive exclusion of school by authorities \\
\hline \multicolumn{2}{|l|}{ Highest qualification completed } \\
\hline No qualification & No qualification \\
\hline ISCED 1 & Primary qualification \\
\hline ISCED 2 & Lower-secondary qualification \\
\hline ISCED 3C & Upper-secondary qualification, 2 years \\
\hline ISCED 3B & Upper-secondary qualification, 3 years \\
\hline ISCED 3A & Upper-secondary qualification, 4 years \\
\hline ISCED 4 & Tertiary qualification \\
\hline
\end{tabular}


Table A.2 Descriptive statistics

\begin{tabular}{|c|c|c|}
\hline Variables & $\%$ & $\mathrm{~N}$ \\
\hline Age (mean) & 22.3 & 496 \\
\hline \multicolumn{3}{|l|}{ Nationality } \\
\hline Swiss & 85.7 & 413 \\
\hline Other nationalities & 14.3 & 69 \\
\hline \multicolumn{3}{|c|}{ Highest qualification completed } \\
\hline No qualification & 1.6 & 8 \\
\hline ISCED 1 & 4.6 & 23 \\
\hline ISCED 2 & 40.5 & 201 \\
\hline ISCED 3C & 35.3 & 175 \\
\hline ISCED 3B & 14.7 & 73 \\
\hline ISCED 3A & 2.8 & 14 \\
\hline ISCED 4 & 0.4 & 2 \\
\hline \multicolumn{3}{|l|}{ ICD-10 Diagnosis } \\
\hline F0 & 3.0 & 15 \\
\hline $\mathrm{F} 2$ & 17.5 & 87 \\
\hline F3 & 6.3 & 31 \\
\hline F4 and F5 & 6.0 & 30 \\
\hline F6 & 21.4 & 106 \\
\hline F7 & 22.2 & 110 \\
\hline F8 & 13.3 & 66 \\
\hline F9 & 10.3 & 51 \\
\hline \multicolumn{3}{|l|}{ Employment situation } \\
\hline Currently employed & 34.5 & 171 \\
\hline Not currently employed & 65.5 & 325 \\
\hline \multicolumn{3}{|l|}{ Sheltered employment } \\
\hline $\begin{array}{l}\text { Currently in sheltered } \\
\text { employment }\end{array}$ & 49.6 & 81 \\
\hline $\begin{array}{l}\text { Currently in } \\
\text { non-sheltered employment }\end{array}$ & 50.4 & 82 \\
\hline
\end{tabular}

Note: Each group of variables sums up to 496 observations except "sheltered employment" where we have information only on individuals who are currently employed (although missing information on this variable for 8 individuals). 